\title{
Technique
}

\section{A guide wire for rapid jejunal biopsies with the Crosby capsule}

\author{
TONY WICKS AND DAVID CLAIN From the Depart- \\ ment of Medicine, University of Rhodesia, and the \\ Salisbury Central Hospital
}

We describe here a technique which facilitates rapid jejunal biopsies using the conventional Crosby capsule. The method was first devised for use in small children in whom there was occasional difficulty in getting the capsule to move from the body or fundus of the stomach towards the pylorus. It has long been our practice initially to check the position of the capsule with an image intensifier after swallowing, to ensure rapid passage. At that time polythene tubing of $1.0 \mathrm{~mm}$ bore was in use with the capsule. After lubrication with paraffin, a Seldinger wire of $0.889 \mathrm{~mm}$ in diameter was passed down the lumen of the tubing as far as the capsule. The inserted wire provided control of the capsule and allowed manipulation through the pylorus.

The technique has now been extended to adults but as the new fully flexible, radioopaque tubing (supplied by Ferraris Development and Engineering Co Ltd) is of larger calibre, wire of $1.194 \mathrm{~mm}$ diameter is used which fits the Seldinger needle PE 205. The wire may be inserted into the tubing before the capsule is swallowed and by pressure on the now semi-rigid tube, the capsule is assisted in its passage to the stomach. The capsule is positioned in the first part of the duodenum under fluoroscopic control with the patient on the right side. The wire is withdrawn and air injected to assist peristalsis. The capsule usually advances through the further parts of duodenum and beyond the duodenojejunal flexure in 10 to 15 minutes.

Occasional difficulty may be encountered in manipulating the capsule in the stomach if it impinges on the greater curvature or anterior wall. This can be obviated either by passing the tube with the patient in the upright position or by lying on the right side. We have on occasion pushed the tube into the jejunum with the wire in situ, but have had difficulty withdrawing the wire from the tubing because of the looping which has occurred.

The technique has been used on 30 adults and 10 children. The speed of obtaining jejunal biopsies is greatly accelerated, and the method is acceptable to both patient and operator.

A Seldinger wire was used by Frič and Lepsik (1965) as a radioopaque marker inside a relatively stiff Odman-Ledin no. 1 arterial catheter but they do not appear to have used the wire to facilitate biopsy by manipulating the capsule.

An alternative method was described by Salem, Salt, and Truelove (1965) and by Evans, Farrow, Harding, and Stewart (1970) using tubing of a larger bore over that of the capsule. We have found this impossible to apply in infants and small children in whom we insert the capsule tubing via the nose, and in adults the larger tube is less well tolerated than a flexible wire within the capsule tubing.

\section{References}

Evans, N., Farrow, L. J., Harding, A., and Stewart, J. S. (1970). New techniques for speeding small intestinal biopsy. Gut, 11, 88-89.

Fric, P., and Lepsik, J. (1965). Use of Odman-Ledin catheter and Seldinger wire with Crosby capsule. Gut, 6, 101.

Salem, S. N., Salt, R. H., and Truelove, S. C. (1965). Crosby small intestinal capsule with radio-opaque tube and latex sheath. Gut, 6, 99-100. 